\title{
Batch extractive distillation of mixture methanol-acetonitrile using aniline as a asolvent
}

\author{
Guangzhong Li", Yang Yu, Peng Bai \\ School of Chemical Engineering and Technology, Tianjin University, Key Laboratory of Systems Bioengineering, Ministry of \\ Education, Tianjin University, Tianjin 300072, China \\ *Corresponding authors: liguangzhong@tju.edu.cn
}

\begin{abstract}
Methanol and acetonitrile form a minimum azeotrope at $336.74 \mathrm{~K}$, which contains methanol 76.89 mas\%. The simulation and the experiment to separate the mixture by batch extractive distillation using aniline as entrainer is performed. Based on the experimental and simulative VLE data, aniline is chosen to be the suitable solvent. The sensitivity analysis about the number of stages, the reflux ratio, the solvent feed stage and the solvent flow rate is conducted to obtain the optimal parameters and configuration of the extractive distillation column with minimal energy requirements. The most appropriate configuration is 30 theoretical stages. The optimal entrainer feeding stage is 8 with a solvent flow rate of $20 \mathrm{~kg} / \mathrm{h}$ and the reflux ratio of 2.0, respectively. The simulation results show the effect of the main variables on the extractive distillation process. The experiment is carried out to corroborate the feasibility of the separation of methanol-acetonitrile by batch extractive distillation.
\end{abstract}

Keywords: Batch extractive distillation; methanol; acetonitrile; aniline; simulation

\section{INTRODUCTION}

Batch distillation (BD) has always been an important part of seasonal, uncertain or low capacity and high-purity chemicals' production. It is a process of key importance in the pharmaceutical and several other industries and in the regeneration of waste solvent mixtures. It is extensively used in laboratories and small production units $^{\mathbf{1 - 3}}$. Extractive distillation(ED) is an important separation method frequently applied in the chemical industry for separating mixtures of components having a relative volatility close to unity. The separation is done by introducing a selectively acting third component, the extractive distillation solvent namely the solvent, with the result that the relative volatility of the mixture to be separated is increased and azeotropes, if present, are overcome $^{4-8}$. Yatim et al. (1993) demonstrated that the batch extractive distillation (BED) can simultaneously provide the advantages of $\mathrm{BD}$ and those of the $\mathrm{ED}$. The feasibility and performance of the BED in batch rectifiers (BR) were also studied experimentally in a pilot plant for the mixture acetone $(A)$-methanol $(B)$ + water (solvent, $E)^{\mathbf{9}-11}$.

Methanol and acetonitrile are extensively used as solvents or reagents in organic chemistry. Acetonitrile has been used extensively as a solvent or as an important fine chemical in the chemical and pharmaceutical production process. A large volume of methanol-acetonitrile solution is generated continuously in the relative processes. A suitable and efficient method to recover the methanol and acetonitrile is necessary. Separation of them with a conventional distillation process is very difficult due to the azeotropic system ${ }^{12}$. Extractive distillation is a preferable way to improve the separation of azeotropic systems and approximate boiling point systems ${ }^{\mathbf{1 0 , 1 1}}$.

In this paper, the simulation for the separation of methanol- acetonitrile azeotropic mixture is carried out to select the suitable solvent and obtain the optimal pa- rameters for batch extractive distillation. Furthermore the results are compared with that procured via experiments.

\section{SOLVENT SCREENING}

In extractive distillation for the separation of azeotropic mixture, a third component named entrainer is required, which modifies the relative volatility of the mixture components ${ }^{13}$. The solvent selection is an important step because the separation effectiveness depends on the interactions between this component and the azeotropic mixture.

\section{VLE simulation}

Several solvents, including aniline, DMF, ethylene glycol and glycerol, are selected to separate methanol and acetonitrile according to the solvent selection rules: thermal stability, low toxicity, higher boiling point, easy recovery, change the relative volatility between the key components, and the selectivity. CHEMCAD 6.0.1 and the thermodynamic package using the Wilson model are used to evaluate the vapor-liquid equilibrium (VLE) with the solvents being added to the binary mixture. The simulation results are shown in Figure 1. Obviously, aniline can increase the relative volatility of the original components to the greatest degree. Therefore it is the most suitable solvent to separate the mixture methanol-acetonitrile.

As for the other solvent, they can also modify the relative volatility between methanol and acetonitrile, especially break the azeotropic condition of the original mixture. However, as shown in Figure 1, the relative volatility does not have such a significant change as for aniline, especially shows a decrease in the low concentration section with other solvents present, which will make the separation difficult. As a result, the separation process will require more stages and energy. 


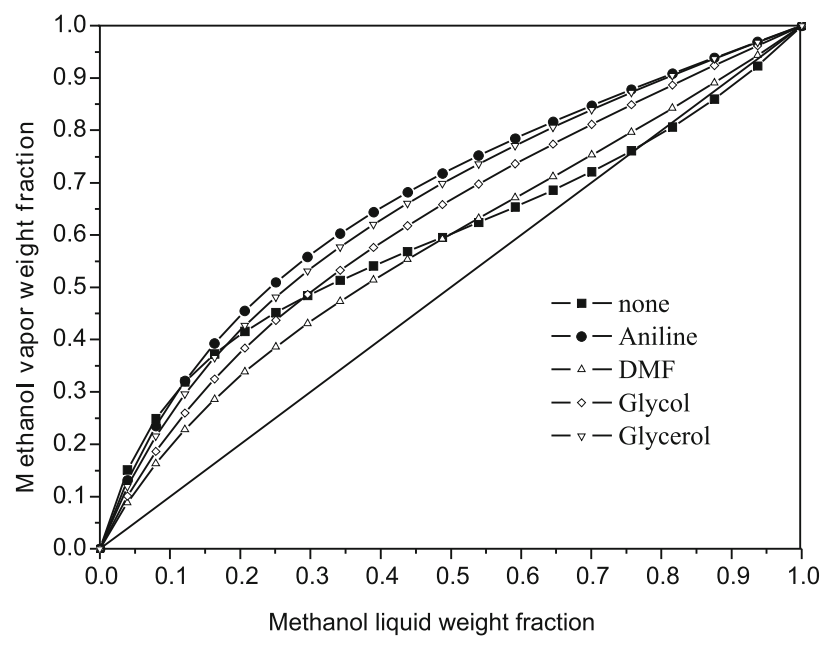

Figure 1. Pseudo-binary $x-y$ plot for the methanol (1)-acetonitrile (2) system with a solvent to feed molar ratio 1.

\section{Residue curve map}

The design and analysis of the extractive distillation process should involve the use of the residue curve maps ${ }^{14}$. These are the tools to determine whether the solvent is or is not the most effective to obtain the desired separation. The residue curve maps for extractive distillation of binary mixtures forming a minimum azeotrope are composed by a stable node that corresponds to the solvent vertex, an unstable node that corresponds to the azeotrope, and the saddle points located at the vertices of the azeotropic mixture, which are summarized in Table 1. Figure 2 presents the residue curve map for the methanol-acetonitrile-aniline system. The azeotropic mixture of methanol (bp $337.68 \mathrm{~K}$ ) and acetonitrile (bp $354.63 \mathrm{~K}$ ) presents a minimum boiling point at 336.74 $\mathrm{K}$ at 1 atm. From Figure 2, it is observed that aniline

Table 1. Mixture investigated for azeotropes at a pressure of $1 \mathrm{~atm}$

\begin{tabular}{|c|c|c|}
\hline Component Name & Classification & $\begin{array}{c}\text { Temperature } \\
(\mathrm{K})\end{array}$ \\
\hline METHANOL & Saddle & 337.68 \\
\hline ACETONITRILE & Saddle & 354.63 \\
\hline ANILINE & Stable Node & 457.03 \\
\hline METHANOL/ & $\begin{array}{c}\text { Unstable } \\
\text { Node }\end{array}$ & 336.74 \\
\hline ACETONITRILE & \multicolumn{2}{|c}{} \\
\hline
\end{tabular}

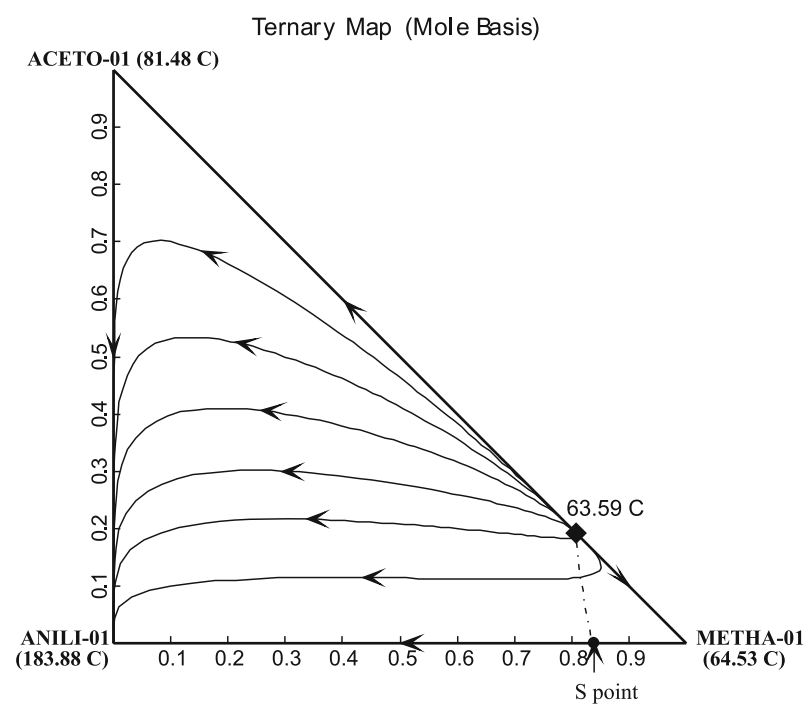

Figure 2. Residue curve map for methanol-acetonitrile-aniline system at $1 \mathrm{~atm}$ calculated using the Wilson model is a feasible solvent for the methanol- acetonitrile separation because the residue curve map has the optimal configuration (stable and unstable nodes, and saddle points) for the extractive distillation.

\section{Experiment and simulation of VLE}

Previous to the simulation, the ternary vapor-liquid equilibrium (VLE) of the methanol-acetonitrile-aniline system was determined experimentally using a modified Othmer still. The experimental apparatus is shown in Figure 3. The mixture of methanol-acetonitrile with different concentrations, with the solvent to feed molar ratio is 1 , are prepared in the still. After the VLE was achieved (constant temperature throughout the system), samples of condensed vapor and liquid were taken for GC analysis. Each assay was made in duplicate. Figure 4 shows the binary diagram obtained excluding the solvent.

Three thermodynamic models (Wilson, NRTL, and UNIQUAC) were studied to determine which model is the most suitable to predict the system performance. It can be concluded that the Wilson model presented the

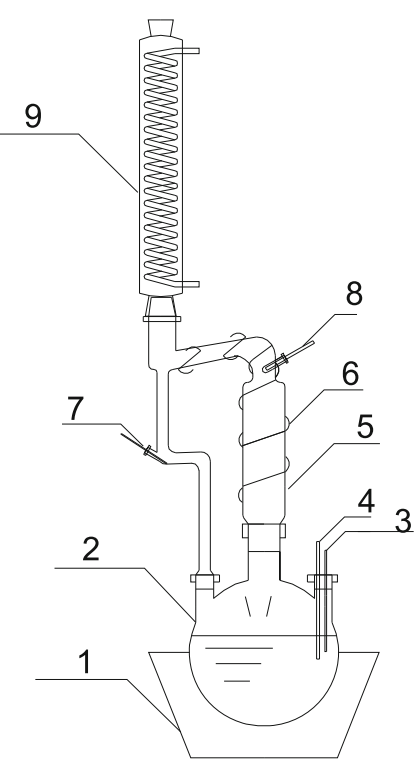

1 - heating jacket; 2 - still; 3 - liquid phase sampling port; 4, 8 metal thermocouple; 5 - Equilibrium chamber; 6 - heat preservation webbing; 7 - vapor phase sampling port; 9 - condenser

Figure 3. Vapor-liquid equilibrium experimental apparatus

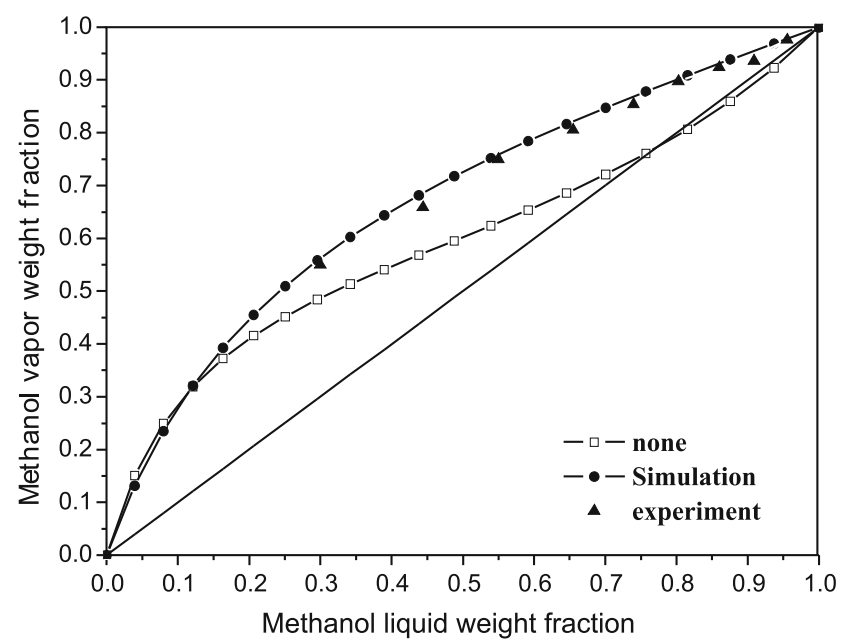

Figure 4. Pseudo-binary $x-y$ plot for the methanol (1) - acetonitrile (2) system with an solvent to feed molar ratio of 1.0 
highest accuracy comparing to the experimental results. The thermodynamic package using the Wilson model was used to evaluate the vapor-liquid equilibrium (VLE). Figure 4 shows the experimental and simulation results of the mixture VLE at atmospheric pressure and the results match well enough.

\section{SIMULATION OF THE METHONAL-ACETONITRILE EXTRACTIVE DISTILLATION}

\section{Rigorous simulation method}

The rigorous simulation are carried out by the CCBATCH module of the CHEMCAD 6.0.1 professional simulator (Chemstations, 2006) applying the simultaneous correction method. The solution method is based on quasi-steady state approximation. The process flow diagram of the extractive distillation process is presented in Figure 5 and the feed conditions of the azeotropic mixture and the entrainer are shown in Table 2.

\section{Sensitivity analysis results}

In batch extractive distillation column, the stages above the feed stage form the solvent recovery section named the rectifying section (RS). The feed stage and the stages below it (including the still) provide the extractive section (ES) of the column. The number of stages for RS and ES has great influence on the purity and recovery of the product. The parameters studied are as follows: the number of stages (NS), the reflux ratio (R), the solvent feed stage, and the solvent flow rate. The initial charge has azeotropic composition.

Table 2. Process Design Initial Parameters

\begin{tabular}{|c|c|}
\hline parameters & value \\
\hline Bottom charge $(\mathrm{kg})$ & 100 \\
\hline Bottom initial temperature $(\mathrm{K})$ & 293.15 \\
\hline Initial charge mass fraction & 76.89 \\
methanol & 23.11 \\
acetonitrile & 293.15 \\
\hline Solvent feed temperature (K) & 5 \\
\hline Distillate mass flow (kg/h) & 0.98 \\
\hline Distillate specified value & 1 \\
\hline pressure (atm) &
\end{tabular}

\section{The number of stages}

Figure 6 shows the influence of the reflux ratio and the number of stages on the top product. It is observed that an increase of reflux ratio causes an increase of the least stages to satisfy the separation. This is because the higher reflux will cause the dilution of the solvent concentration in the liquid phase, which requires more stages for the light component extraction. The product accumulation in the tank has a small increase as an increase of reflux ratio. When the reflux ratio is specified, the higher number of stages does not cause the great increase of product; on the contrary, the increase is very small. From Figure 6, the results reveal that the BED process can be operated at a reflux ratio between 1.0 and 4.0 with a number of stages more than 30 .

The effect of the reflux ratio and number of stages on the reboiler duties is presented in Figures 7. For all the cases, reboiler duties do not change with the number of

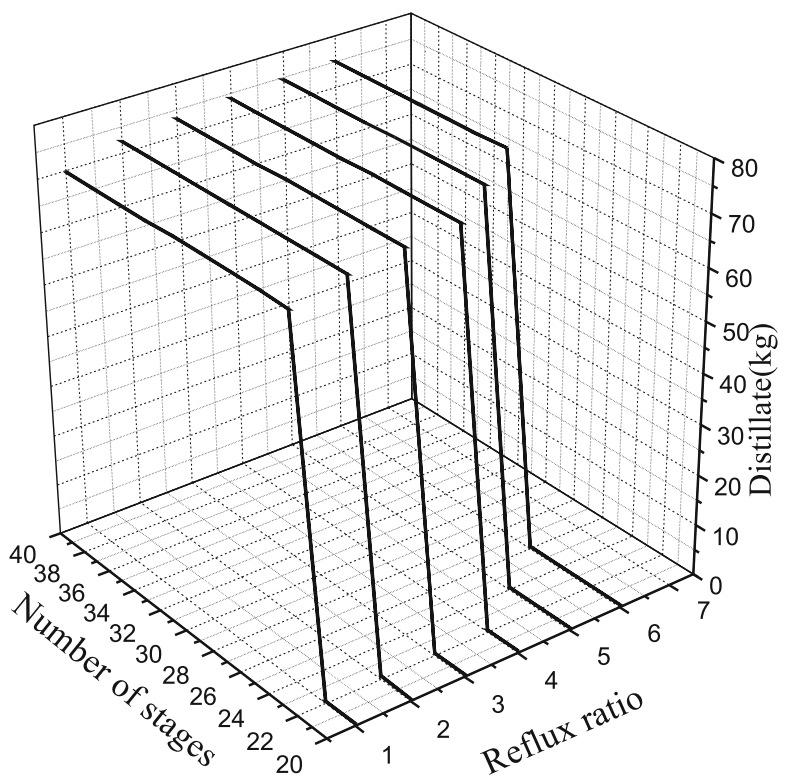

Figure 6. Number of stages and reflux ratio influence on the distillate mass. Operational conditions: solvent feed temperature 20, solvent feed stage 8 , solvent flow rate $20 \mathrm{~kg} / \mathrm{h}$.

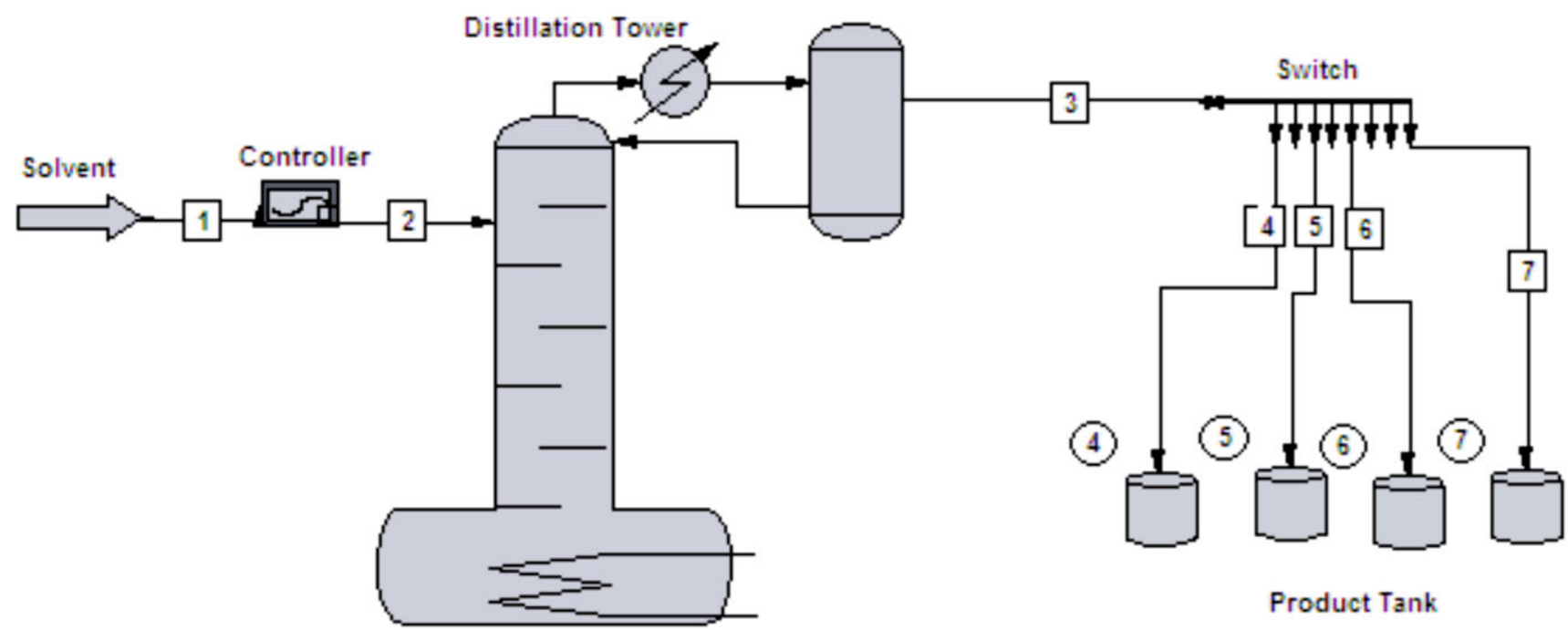

Figure 5. Process flow diagram for the extractive distillation column 


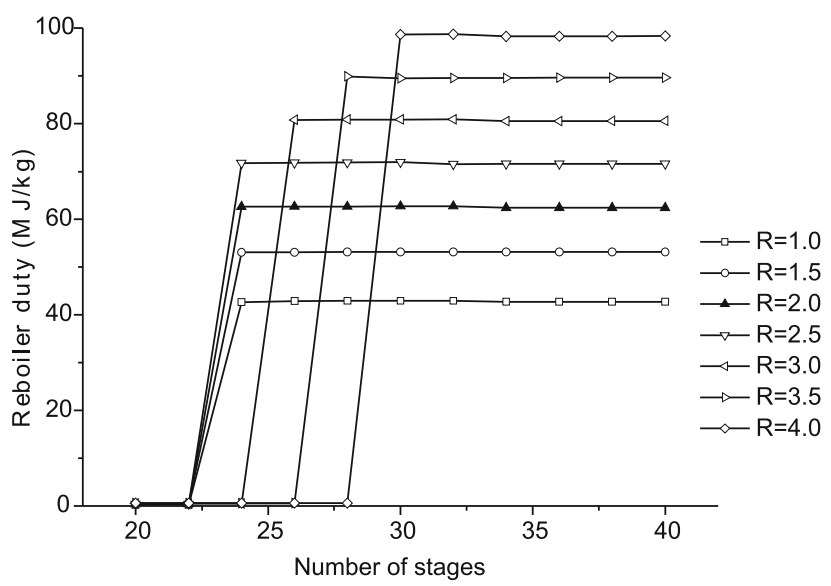

Figure 7. Number of stages and reflux ratio influence on the reboiler duty. Operational conditions: solvent feed temperature 20 , solvent feed stage 8 , solvent flow rate $20 \mathrm{~kg} / \mathrm{h}$.

stages. Nevertheless, the reflux ratio has an important influence on the column energy consumption. Heating requirements presented a direct proportional linear relationship with the reflux ratio. Through the analysis, both of the energy consumption and recovery are reasonable at the reflux ratio 2 .

\section{The number of $R S$ stages}

For a specific BED process, there is a minimum and a maximum number of rectifying trays. The distillate purity decreases below its specified value either the number of RS stages below the minimum or above the maximum one. The influence of the number of RS stages on the product composition recovery and the energy consumption is shown in Table 3. It can be concluded that the minimum number of RS stages is 3 and the maximum one is 11 obviously. If the RS only has 2 or less stages, the liquid phase comes from the feed stage, which is composed of methanol and the solvent, cannot be separated quite well and the distillate purity is below its specified value. Contrarily, more than 11 stages in RS will cause a concentration decrease of the eligible distillate toward the azeotropic mixture of methanol and acetonitrile again. However, the condenser and reboiler duties do not have a great change with the stage number increasing. It is observed in Table 3 that stage 8 is a feasible one to feed the solvent.

Table 3. Influence of the Number of RS Trays on the Recovery and Energy Consumption

\begin{tabular}{|c|c|c|c|}
\hline $\begin{array}{l}\text { Number of } \\
\text { rectifying } \\
\text { Trays }\end{array}$ & Recovery & $\begin{array}{c}\text { Reboiler } \\
\text { duty(MJ/kg) }\end{array}$ & $\begin{array}{c}\text { Condenser } \\
\text { duty (MJ/kg) }\end{array}$ \\
\hline 2 & 0 & - & - \\
\hline 3 & 0.95589 & 62.7312 & -48.5274 \\
\hline 5 & 0.955893 & 62.715 & -48.522 \\
\hline 7 & 0.955895 & 62.6904 & -48.5142 \\
\hline 9 & 0.955894 & 62.6544 & -48.5024 \\
\hline 11 & 0.955899 & 62.6014 & -48.4854 \\
\hline 12 & 0 & - & - \\
\hline
\end{tabular}

\section{Reflux ratio}

The reflux ratio is very important for the distillation process, which significantly affects the product purity and the energy requirement at the same time. It is observed

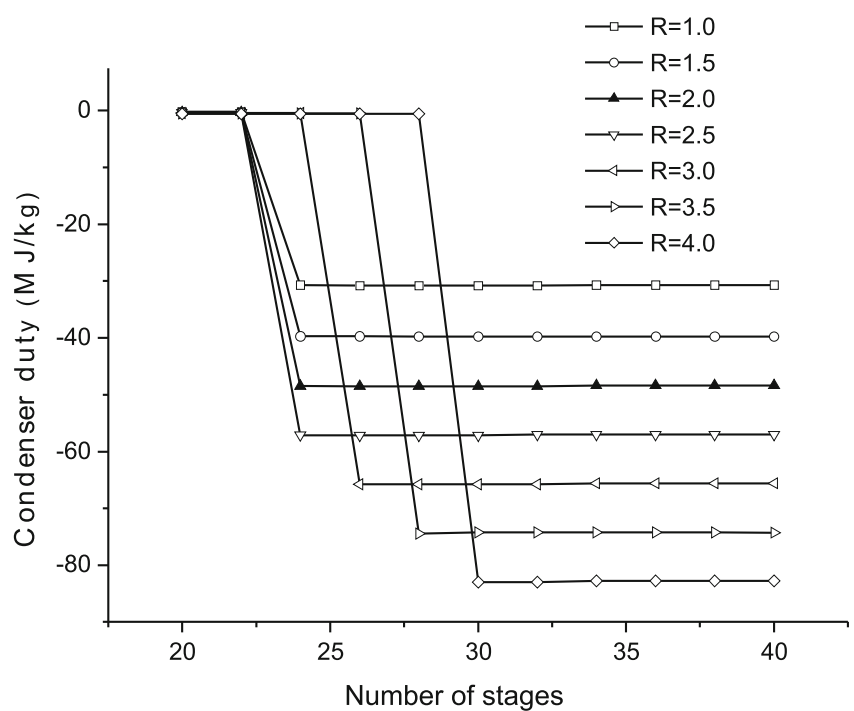

Figure 8. Number of stages and reflux ratio influence on the condenser duty. Operational conditions: solvent feed temperature 20 , solvent feed stage 8 , solvent flow rate $20 \mathrm{~kg} / \mathrm{h}$.

in Figure 8, the recovery, condenser duty and reboiler duty all increase with the reflux ratio increasing. Especially the energy requirement has a proportional linear change comparing with the small recovery increase at $\mathrm{R}$ between 1.0 and 4.0. However, the methanol concentration in the top does not satisfy the purity requirement at reflux ratio above 4.0 , and no eligible product can be obtained as a result. That is because the higher reflux rates brings about the dilution of the solvent in the liquid phase, and the reflux causes that the efficiency of the separation between methanol and acetonitrile decreases. Reversely, the reduction of the reflux ratio increases the concentration of the entrainer at the stages and in the case of the relative volatility of mixture rises with increasing the solvent concentration in a monotone way. Through the analysis, it can be concluded that the high purity and recovery of methanol are obtained at reflux ratio 2.0.

\section{Solvent flow rate}

The flow rate of the solvent is one of the most important operational parameters of the BED. If the azeotrpic mixture can be separated using a particular solvent, there must be a minimum flow rate, which depends on the reflux ratio and the compositions of the feed and distillate at a specified distillate rate ${ }^{11,15}$. The minimum solvent flow rate is that where (under the given vapor flow rate) located in the intersection of the isovolatility curve and the methanol-aniline edge, $\mathrm{S}$ point shown in Figure 2. $\boldsymbol{F}_{\min }$ is calculated through equation (1) using material balance.

$F_{\min }=\frac{V\left(x_{s}-y *\right)}{z-x_{s}}$

As can be seen in Figure 2, $x_{\mathrm{s}}$ is 0.16 (mole fraction), the corresponding $\mathrm{y}^{*}$ can be obtained according to the VLE data of methanol-aniline. With the specified operating conditions- infinite reflux, the minimum solvent flow rate is computed and its value is $5.60 \mathrm{~kg} / \mathrm{h}$. The minimum entrainer flow rate for operation under finite $\mathrm{R}$ is lower than its value for that under infinite R. Hence, the minimum solvent flow rate for the whole process is $5.60 \mathrm{~kg} / \mathrm{h}$. Just when the solvent feed rate is over the 
Table 4. Solvent flow rate influence on the energy consumption and recovery, Operational conditions: NS 30, reflux ratio 2, solvent feed temperature $293.15 \mathrm{~K}$, solvent feed stage 8

\begin{tabular}{|c|c|c|c|}
\hline $\begin{array}{c}\text { Solvent flow } \\
\text { rate }(\mathrm{kg} / \mathrm{h})\end{array}$ & Recovery & $\begin{array}{c}\text { Reboiler } \\
\text { duty(MJ/kg) }\end{array}$ & $\begin{array}{c}\text { Condenser duty } \\
(\mathrm{MJ} / \mathrm{kg})\end{array}$ \\
\hline 15 & 0 & - & - \\
\hline 20 & 0.955895 & 62.6904 & -48.5142 \\
\hline 25 & 0.955887 & 67.1326 & -48.5338 \\
\hline 30 & 0.955898 & 71.6968 & -48.5396 \\
\hline 35 & 0.955895 & 76.3718 & -48.5414 \\
\hline
\end{tabular}

minimum, the separation of azeotropic mixture is feasible.

Table 4 shows the influence of the solvent flow rate on the methanol recovery and unit energy consumption. From the results, the reboiler duty presents significant changes as the solvent flow rate increase. On the contrary, the condenser duty and recovery almost remain constant when the separation is feasible. This is because an increase of aniline flow rate needs more heat energy to heat up the solvent under the feed stage, the reboiler duty increases as a result. It can be concluded that the methanol purity does not reach the criterion at the solvent flow rate $15 \mathrm{~kg} / \mathrm{h}$ under the operating parameters, and $20 \mathrm{~kg} / \mathrm{h}$ is a suitable value satisfied the recovery requirement with lower condenser and reboiler duties.

\section{Simulation results}

Simulation for the separation of methanol-acetonitrile azeotropic mixture is conducted with aniline as the solvent, and the optimal parameters for the extractive distillation is presented in Table 5. As a result, the methanol with a mass purity $99.35 \%$ is obtained and the recovery is $95.59 \%$.

Table 5. Extractive Distillation Parameters

\begin{tabular}{|l|c|}
\hline parameter & value \\
\hline number of stages & 30 \\
\hline reflux ratio & 2.0 \\
\hline Solvent feed stage & 8 \\
\hline Solvent flow rate $(\mathrm{kg} / \mathrm{h})$ & 20 \\
\hline Solvent feed temperature $\left({ }^{\circ} \mathrm{C}\right)$ & 20 \\
\hline Energy consumption $(\mathrm{MJ} / \mathrm{kg})$ & \\
Condenser duty & -48.51 \\
Reboiler duty & 62.69 \\
\hline
\end{tabular}

\section{Extractive distillation process}

Basic steps of the BED

A complete BED process consists of the following basic steps ${ }^{17}$ :

1. Operation under the total reflux without solvent feeding.

2. Operation under infinite reflux ratio with solvent feeding (purification of the distillate).

3. Operation under the finite reflux ratio with solvent feeding (production of $\mathrm{A}$ ).

4. Operation under the finite reflux ratio without solvent feeding (separation of the component B from the solvent).

The experiment is carried out in a pilot-plant. The laboratory-scale BED column used in this study was shown in Fig. 6. It consists of a still (reboiler) of 2 liter in capacity, a condenser, and a packed column of $50 \mathrm{~mm}$ inner diameter. The column was packed with stainless steel Dixon Rings of $3 \mathrm{~mm}$ in diameter and $3 \mathrm{~mm}$ in length. The height of the packed section is $1500 \mathrm{~mm}$.

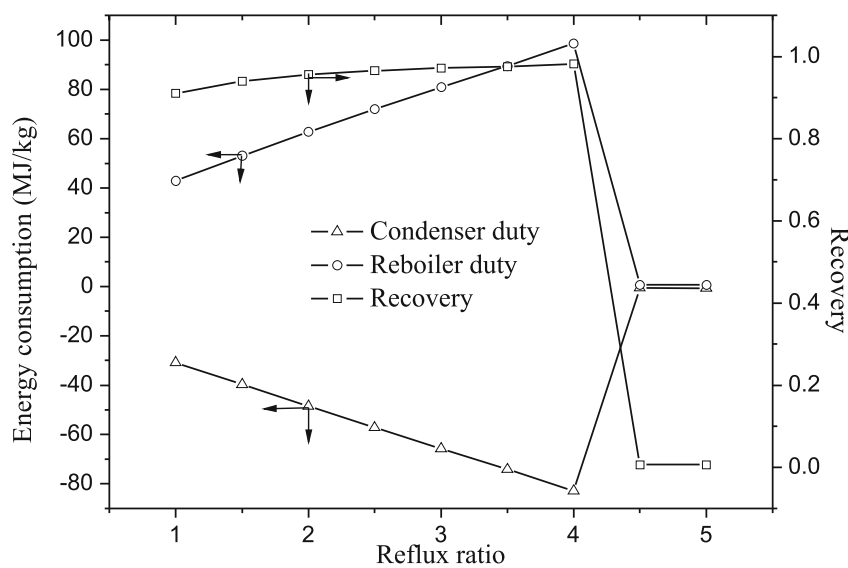

Figure 9. Reflux ratio influence on the energy consumption and recovery. Operational conditions: NS 30, solvent feed temperature 20 , solvent feed stage 8 , and solvent flow rate $20 \mathrm{~kg} / \mathrm{h}$

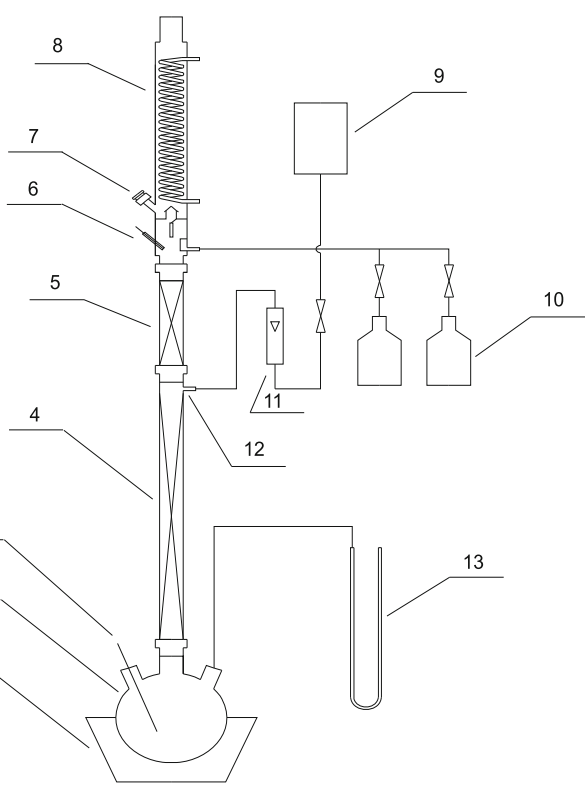

(1) heating jacket; (2) still; $(3,6)$ metal thermocouple; (4) stripping section; (5) rectifying section; (7) sampling port; (8) condenser; (9) solvent storage tank; (10) product receiver; (11) flowmeter; (12) solvent feed port

Figure 10. Experimental apparatus of the batch extractive distillation

Measured by the test mixture ethanol-isopropanol, the total theoretical trays number is 30 . The solvent feeding spot splits the column into the rectifying section and the stripping section. The height of the rectifying section is $400 \mathrm{~mm}$, while that of the stripping section is $1100 \mathrm{~mm}$.

The batch extractive distillation column involves 30 theoretical stages, $7 \mathrm{RS}$ stages, and the operating heat duty is fixed at $400 \mathrm{~W}$. The initial mass fraction of methanol in the still is 0.75 . During step 2, the solvent feed rate is $15 \mathrm{ml} / \mathrm{min}$. Figure 10 reflects the results of step 1 and 2. It is observed in the figure that the solvent is an effective agent and methanol with a high purity can be obtained in the top of distillation column.

Figure 11 shows the simulation of the extractive distillation process, which involves step 3 and 4 of the above mentioned basic steps, while step 1 and 2 are neglected in the simulation. Step 4 is done for the recuperation of the solvent. Two kinds of slop cut, methanol-acetonitrile and acetonitrile-aniline, are obtained during this period. 


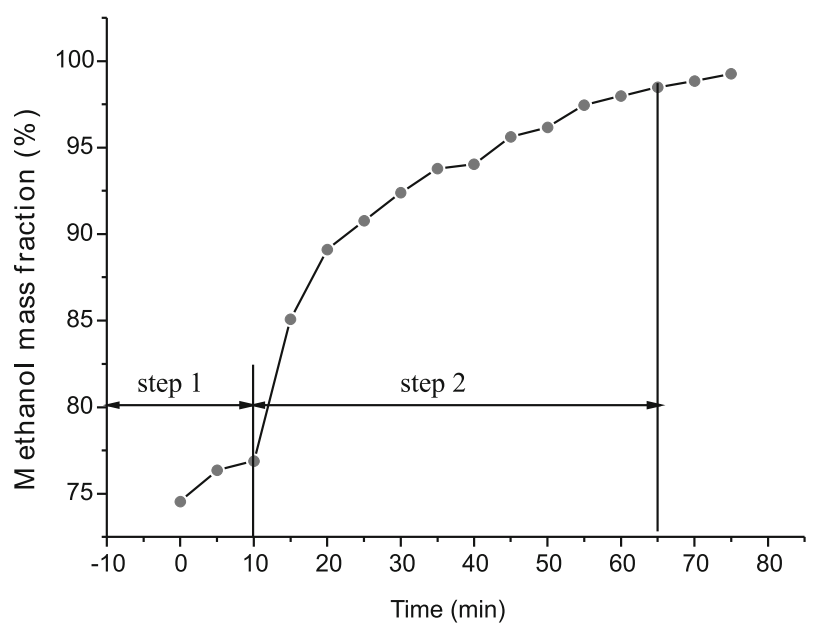

Figure 11. The experimental result of batch extractive distillaion

However, the separation of methanol-acetonitrile using aniline as the solvent is feasible.

\section{CONCLUSION}

For the methanol-acetonitrile-aniline mixture, the vapor-liquid equilibrium experiment and corresponding simulation using Wilson model are performed, and the simulation results agree well with the experimental results. Several potential solvents are also tested theoretically by VLE calculations, and aniline is the most appropriate agent for batch extractive distillation. The feasibility of the BED process was confirmed via simulation and laboratory experiments. It also allows us to determine the most suitable configuration of the distillation apparatus and the operating conditions for the separation of the azeotropic mixture. To obtain the optimal conditions and configuration for the extractive and recovery columns, sensitivity analysis was done. The solvent feed rate has a close relationship with the reflux ratio in batch extractive distillation. It can be seen from the results that the separation of azeotropic mixtures methanol-acetonitrile by batch extractive distillation is feasible.

\section{Appendix}

Appendix 1. Temperature (K) - dependent binary parameters

\begin{tabular}{|c|c|c|c|}
\hline Component $\mathrm{i}$ & Methanol & Methanol & Acetonitrile \\
\hline Component j & Acetonitrile & Aniline & Aniline \\
\hline Aij & 0.0 & 0.0 & -0.464000000 \\
\hline Aji & 0.0 & 0.0 & 0.113500000 \\
\hline $\mathrm{Bij}$ & -152.6753000 & -108.2928000 & -23.67000000 \\
\hline $\mathrm{Bji}$ & -195.5468000 & -175.9480000 & 132.2397000 \\
\hline
\end{tabular}

\section{LITERATURE CITED}

1. Mujtaba, I.M., (2004). Batch Distillation: Design and Operation. Imperial College Press ISBN: 1-86094-437-X.

2. Kim, K.J. \& Diwekar, U.M., (2001). New area in batch distillation: computer aided analysis, optimal design and control. Rev. Chem. Eng. 17, 111-164. DOI: 10.1515/REVCE.2001.17.2.111.

3. Stichlmair, J.G. \& Fair, J.R., (1998). Distillation, Principles and Practice. Wiley-VCH, New York ISBN: 0-471-25242-7.

4. Van Kaam, R., Rodriguez-Donis, I. \& Gerbaud, V., (2008). Heterogeneous extractive batch distillation of chloroform-methanol-water: Feasibility and experiments. Chem. Eng. Sci. 63, 78-94. DOI:10.1016/j.ces.2007.09.005.

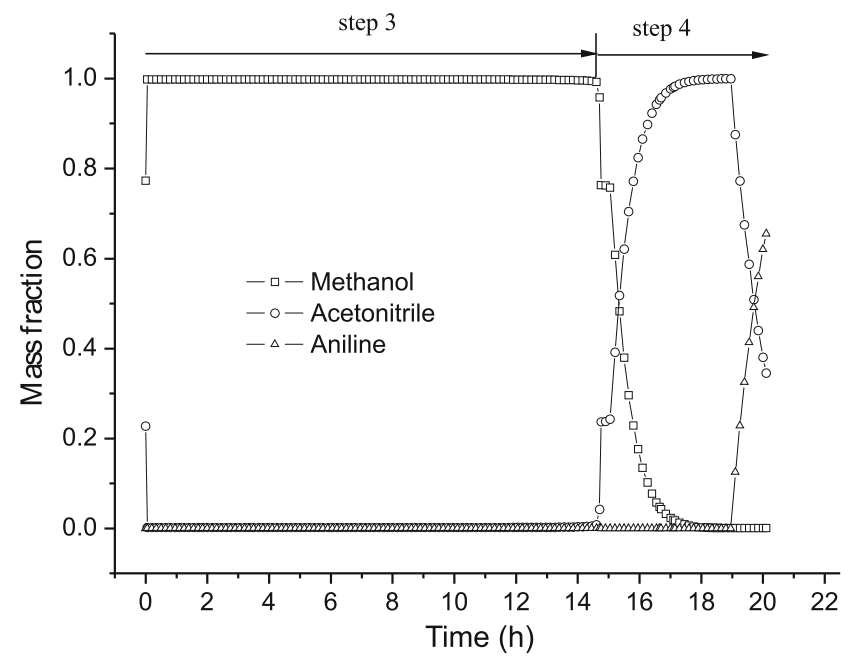

Figure 12. The simulation result of batch extractive distillation

5. Wentink, A.E., Kuipers, N.J.M., Haanb, A.B., Scholtz, J. \& Mulder, H., (2007). Olefin isomer separation by reactive extractive distillation: modeling of vapour-liquid equilibria and conceptual design for 1-hexene purification. Chem. Eng. Proc. 46, 800-809. DOI: 10.1016/j.cep.2007.03.009.

6. Xu, S. \& Wang, H., (2006). A New entrainer for separation of tetrahydrofuran-water azeotropic mixture by extractive distillation. Chem. Eng. Proc. 45, 954-958. DOI: 10.1016/j. cep.2006.02.001.

7. Lei, Z., Zhoua, R., Duana, Z., (2002). Process improvement on separating $\mathrm{C} 4$ by extractive distillation. Chem. Eng. J. 85, 379-386. DOI: 10.1016/S1385-8947(01).

8. Pinto, R.T.P., Wolf-Maciel, M.R. \& Lintomen, L., (2000). Saline extractive distillation process for ethanol purification. Comput. Chem. Eng. 24, 1689-1694. DOI: 10.1016/S00981354(00)00455-5.

9. Lang, P., Kovacs, Gy., Kotai, B., Gaal-Szilagyi, J. \& Modla, G., (2006). Industrial Application of a New Batch Extractive Distillation Operational Policy. Distillation and Absorption 2006 Symposium Series. (pp. 830-839, No. 152).

10. Lelkes, Z., Lang, P., Benadda, B., Otterbein, M. \& Moszkowicz, P., (1998a). Batch extractive distillation: the process and the operational policies. Chem. Eng. Sci. 53, 1331-1348. DOI: 10.1016/S0009-2509(97)00420-X.

11. Lelkes, Z., Lang, P., Benadda, B. \& Moszkowicz, P., (1998b). Feasibility of extractive distillation in a batch rectifier. AIChE J. 44, 810-822. DOI: 10.1002/aic.690440406.

12. Amadeu Sum, K. \& Stanley Sandler, I., (2002). Prediction of the phase behavior of acetonitrile and methanol with ab initio pair potentials. II. The mixture. J. Chem. Phys. 116, 7636-7644. DOI: 10.1063/1.1464823.

13. Batista, E. \& Meirelles, A., (1997). Simulation and thermal integration SRV in extractive distillation column. $J$. Chem. Eng. Jpn. 3, 45-51. DOI:10.1252/jcej.30.45.

14. Doherty, M. \& Malone, M., (2001). Conceptual Design of Distillation Systems. McGraw Hill: New York.

15. Laroche, L., Bekiaris, N., Andersen, H.W. \& Morari, M., (1991). Homogeneous Azeotropic Distillation: Comparing Entrainers. Can. J . of Chem. Eng. 69, 1302-1319. DOI: 10.1002/ cjce.5450690611.

16. Yatim, H., Moszkowicz, P., Otterbein, M. \& Lang, P., (1993). Dynamic simulation of a batch extractive distillation process. Comput. Chem. Eng. 17, 57-62. DOI: 10.1016/00981354(93)80209-6. 